\title{
Local languages: Good for the informal marketplace but not for the formal classroom?
}

Zubeida Desai

\begin{abstract}
The maxim that 'Languages develop through use, particularly in high domains such as education and the courts' was propagated by Neville Alexander. He was committed to 'intellectualising African languages'. In the spirit of his legacy, this article makes a case for using local languages, also referred to as mother tongues, as mediums of instruction. In making this case, two interrelated perspectives on the role of African languages in the broader society, are critiqued. The first perspective argues that languages evolve on their own, and calls for a multilingualism from below. The second perspective is critical of the term 'mother tongue', and by implication mother-tongue education. The article also critically examines language in education developments in South Africa, in particular the 1.9.97 Language in Education Policy. It argues that one of the reasons for poor learner performance is current language practices, where the language of instruction shifts abruptly to English at the beginning of Grade 4. Examples of learner performance are given from a study the author conducted in Khayelitsha in the Western Cape. The term 'mother tongue' is defined in relation to these critiques. The article concludes by stating that current practices in South Africa continue to privilege English- and Afrikaans-speaking pupils. Drawing on the work of Alexander and others, it argues that linguistic practices from below, regardless of how innovative they are, cannot change power dynamics in unequal societies such as South Africa. It is only when languages are used in high domains such as education that they develop fully.
\end{abstract}

Keywords: Alexander, economic diglossia, English, hegemony, mother tongue, multilingualism

\section{Introduction}

For local languages to gain real currency in South Africa (and elsewhere) they need to be used in high domains such as education. In this regard, I make a case for mother-tongue education, particularly at school level, to enable pupils to understand what they are learning. In making this case, I critique two inter-related perspectives on the role of local languages in the broader society, but particularly in the domain of education. The first perspective views language as a living phenomenon that cannot be regulated easily, as it has a life of its own. Such a view has led to concepts such as 'multilingualism from below' and 'linguistic citizenship' (Stroud and Heugh 2003) being widely propagated. Proponents of this view valourise 'unofficial local varieties' as opposed to what they refer to as 'essentialist identities of standard languages' (Blommaert 2001; Stroud and Heugh 2003). These 'unofficial local varieties' are seen 
as examples of 'multilingualism from below' and therefore to be celebrated, whilst standard varieties are seen as static and essentialist. The second perspective draws on the first and is a criticism of the notion of mother-tongue education. Two prominent proponents of this perspective are Makoni and Pennycook (2007; see also Makoni 2003). The main thrust of their criticism is directed at the ideologically laden nature of the term 'mother tongue' and its corollary 'mother-tongue education'. Referring to African languages, they argue that, because there is a disjuncture between the 'standard' variety and the language used in communities, it would not be in the pupils' interests to be taught in their mother tongues, since the variety used at school would be the standard one - which would be alien to pupils.

Of late, proponents of multilingualism - particularly in developing countries - have tended to focus on the use of local languages in the non-formal sector, or what I refer to as the marketplace (for insight into the growing literature on landscape linguistics and the role of language in the informal sector see Deumert et al. 2005; Gorter 2009; Makoni 2009). Many of these proponents come up with a host of arguments why local languages are difficult to use in formal education, particularly as languages of instruction. I argue that if we confine local languages to the marketplace, we are not going to change the power dynamics in unequal societies such as South Africa. For this to happen, local languages will, for example, have to be used as media of instruction in schools. This is a point taken up very strongly by Tsui and Tollefson (2004:2) who argue:

Medium of instruction is the most powerful means of maintaining and revitalising a language and a culture .... Medium-of-instruction policy determines which social and linguistic groups have access to political and economic opportunities, and which groups are disenfranchised. It is therefore a key means of power (re)distribution and social (re)construction, as well as a key arena in which political conflicts among countries and ethnolinguistic, social and political groups are realized.

This view is echoed by Fishman and Fishman (2000). In a festschrift on the occasion of the 6oth birthday of the renowned sociolinguist and language activist, Tove Skutnabb-Kangas, Fishman and Fishman (2000:24-25) distinguish between what they call 'permissive language defense' and 'active language defense'. The former refers to a mere tolerance of multilingualism, whilst the latter involves actual intervention. However, the authors argue that many countries, and their citizens, pay lip-service to multilingualism. In their words, 'most of the active language defense on 
record is more symbolic than substantive ... Effective language defense requires more than window dressing' (ibid:25). This view, which was actively promoted by the late Alexander, is captured very eloquently in his recent collection of essays published posthumously (Alexander 2013:101-102) where he warns against the potential danger of a 'functional multilingualism' approach resulting in 'economic diglossia'. In his words:

A strand of analysis that attempts to view the political economy of language in terms of 'functional multilingualism' in economic life runs the risk, in my opinion, of promoting a kind of economic diglossia where the 'minority' languages are confined as instruments of communication in the processes of production, exchange and distribution to the so-called informal sector, as against the nationally dominant languages (in Africa, these are almost without exception languages of European origin) that perform these powerful functions in the 'formal' economy .... In Africa specifically, the languages of the majority of the people have to become the dominant languages, in whatever combinations, in the economy, taken as a whole, of each individual country (ibid.).

My entry point into the above conversation, however, is as a teacher who is concerned about promoting pupils' 'epistemological access' to learning and knowledge, as opposed to their institutional access (Morrow 1993). There is no disputing that language is an essential tool in the learning process. Equally, there would be no disputing that for a language to be used as a tool for learning, pupils need to be familiar with and reasonably proficient in that language. In South Africa today, the majority of school pupils need to master both disciplinary knowledge in a language they are competent in, and in English as a language of communication and education. In other words, an approach which furthers pupils' proficiency in their mother tongue as well as in English, is required. What prevents this from happening effectively?

\section{Language in education developments in South Africa}

Instruction in local languages is a controversial issue in South Africa due to historical, social and political factors relating to colonialism and apartheid. South Africa's history under colonialism and apartheid has led to a negative image of African languages in education, as they were associated with inequality and segregation. The apartheid language policy, which interestingly extended the use of African languages in education, was driven by discriminatory principles aimed at ghettoising Africans and segregating South Africans along racial lines. For example, the Bantu Education Act of 1953, which implemented mother-tongue education for eight years of schooling, had ulterior motives in that it blocked African pupils' access to better 
education in a number of ways, including through the unequal distribution of resources and facilities, and by not providing them with real access to English, a language of wider communication which has currency (Hartshorne 1992; Heugh 2000). English has always been taught as a subject in schools catering for African language speakers, but often by teachers who themselves are not very proficient in the language. Despite technological advances, exposure to English remains limited for many African pupils, particularly in rural areas. The situation continues to this day, almost 20 years after apartheid officially ended.

One of the post-apartheid developments in language was the adoption of a new language-in-education policy (LIEP) in July 1997. The actual policy proposals consist of two sections - Languages as subjects, and Language/s of learning and teaching. The latter section consists of one sentence, which reads as follows: 'The language(s) of learning and teaching in a public school must be (an) official language(s)' (DoE 1997:6).

Broadly speaking, the aims of the policy are to facilitate learning and promote communication amongst South Africans through the development of 'additive multilingualism'. However, in practice, their effect might be to counter both these aims. Except for Grades 10-12, only one language (as opposed to two prior to 1994) is now compulsory for promotion purposes. This could result in pupils being less multilingual (in a formal sense) than in the past. Although the policy document represents a serious attempt to address the linguistic inequalities of the past, a number of implicit tensions run through the document. I will focus on what I consider to be one of the main tensions - the 'choice factor'. Despite the fact that the Soweto uprising of 1976 serves as a grim reminder that no state can afford to impose a language policy on pupils, I would argue that the new policy document errs on the side of caution by allowing too much choice (see Desai and Taylor [1997] in this regard). Let me explain. During the apartheid era, promoting the use of African languages as languages of learning was often perceived as an attempt to 'ghettoise' African pupils and deny them access to mainstream South African life. This perception persists. Therefore, unless such individual choice is accompanied by a public awareness campaign around language and learning issues, and a massive injection of resources (both material and human), the prejudices of the past are likely to militate against individual pupils choosing African languages as languages of learning. In my opinion, the state would have to play a more interventionist role if it wishes to extend the use of African languages as languages of learning, beyond the initial years of schooling. 
The 'choice factor' is further compounded by the pull of globalisation. The argument for a mainly English policy is often based on the premise that South Africans can compete internationally only through the medium of English. As Chinua Achebe (in Ngugi 1986:9) puts it, 'the fatalistic logic of the unassailable position of English' takes over. If pupils were acquiring English effectively, such thinking would pose no problem, but English remains an unattainable2 goal for most pupils - not only as a subject, but also as a language through which pupils can access knowledge. There are, of course, exceptions, particularly in schools which historically catered for white pupils. My focus is on the majority of pupils in rural areas and urban township schools, where English is not highly visible (Deumert et al. 2005).

In practice, a transition model is applied in that African languages are used for the first three years of schooling only as transition to English as medium of instruction (MoI) in Grade 4. Although it is not explicitly stated in the policy that English should be the MoI after Grade 3, parents perceive the use of African languages as languages of instruction as a way to block pupils' access to socio-economic avenues associated with competence in English (De Klerk, V 2002)

Obviously, everyone would like to be proficient in the language(s) of the economy. Thus parents or school governing bodies at many schools choose English as an MoI for their children (ibid.). The main concern in this regard, however, is that despite the early shift to English as MoI, many African pupils - especially in the former Department of Education and Training (DET) schools3 - show low levels of English competence by the time they enter tertiary education (i.e., after nine years of English MoI). Naturally, this may be associated with a number of factors, such as the level of the teachers' competence in English, the amount of exposure to English, how English as a language is taught in African schools, etc. Certainly, these factors influence pupils' acquisition and construction of knowledge, which is important not only in academic terms, but also for socio-economic advancement. Unfortunately, the hegemony of English mainly impacts negatively on those who were disadvantaged in the past.

The hegemony of English may also be explained in terms of intellectual dependency, in that it is perceived to be the gatekeeper to academic knowledge. That is, those who are competent in English usually have better epistemological access to education than those with limited proficiency in the language. The effects of the use of English as a medium in South African classrooms are evident in a number of research studies, which show a strong correlation between the language of instruction and academic 
performance (Desai 2003, 2012; Langenhoven 2005; Nomlomo 2007; Ramirez et al. 1991; Thomas and Collier 2002).

\section{Pupils' performance in South Africa}

Recent data from the Progress in International Reading Literacy Study (PIRLS) (Howie et al. 2008) indicate that South African pupils perform poorly:

[T] he vast majority of South African pupils are not proficient readers as measured by PIRLS .... South African reading performance does not compare with Grade 4 pupils internationally despite being on average 1 to 2 years older than their international counterparts .. The extremely low performance of the children writing in African languages is not a surprise given the political heritage of the country ... (Howie et al. 2008, n.p.4).

The authors attribute the low reading literacy levels of pupils who are African language speakers to a range of factors, including

$[\mathrm{u}]$ nderresourcing, poor teaching practices, inadequate training in reading practices and lack of available resources for the indigenous languages, a lack of motivation to alter the situation, the oral tradition of the indigenous languages ... (ibid.).

The results of the Annual National Assessments (ANAs) conducted by the Department of Basic Education in 2011, based on the grades pupils were in during 2010, also indicate poor reading performance at Grade 3 and 6 levels.

A study profiling the writing abilities of Grades 4 and 7 pupils in both their mother tongue, Xhosa, and in English, the official MoI from Grade 4 at a school located in Khayelitsha in the Western Cape, indicates similar poor performance in English, particularly at Grade 4 level (Desai 2003, 2012). Three written tasks, which consisted of a narrative piece of writing, a reading comprehension exercise, and an expository piece of writing, were administered to the pupils in both languages. The purpose of the exercise was to examine some of the implications for educational language policy of the differences in performance in the two languages. In this article the focus is only on the narrative task.

Below are two snapshots: the first of a Grade 4 pupil's narrative writing based on a picture story and the second of a Grade 7 pupil's narrative writing based on the same story. For both grades, the first example is a narrative piece written by the pupil in the mother tongue, Xhosa. The second example is the English translation5 of the Xhosa 
piece in the first example, and the third example is the same pupil's narrative piece written in English (see Desai 2003 and 2012 for more information on this project).

Grade 4 pupil

- First example

\section{In Xhosa}

Kwakukho utata waza wabeka ibhokisi yakhe phantsi encokola notata wakhe kwasukha kwathi gqi omnye ubhuti wathatha ibhoks yala tata wabaleka waleqwa ngumntwana omnye wakhalisa impempe omnye emkhemba wabaleka wayo kuqabela imoto wayiqhuba kakhulu abanye bavula ibhokisi kwavela inyoka wathuswa yinyoka kwade kwathaka idimasi.

- Second example

\section{English translation of first example}

There was a father (old man) who put his box down, conversing with his father. Then a certain young man (brother) appeared and took that old man's box and ran away. He was chased by a child and the one blew a whistle, and the other one pointed at him. He ran away with it and got into the car and drove very fast. The others opened the box and a big snake. The other was shocked by the snake and his sunglasses fell down.

- Third example

\section{$\underline{\text { In English }}$}

Once upon a time

Long long ago

Ly Buter uteatsha fourboy late my father

I taket my tyesi

I goiu my father is goiu boeke

Look my boy

Grade 7 pupil

- First example

In Xhosa

Abakhuthuzi Ababini 
Ngenye imini kukho umntu ongutata waye se airport, waye me umcha waye lindele ukuba kufike inqwelo moya.

Wathi esame njalo kwathi gqi abafana ababini bagqiba ukuba mabathathe imantyi yalotata. Omnye wabo wayakulo tata wafika wabuza ngezinto ezibheke emacaleni. Wabuza lotata ukuba ndingaku nceda ngantoni wabe embuza ngezi zinto zingekhoya. Elinye eli isela belishiyekile lambona ukuba akamjonganga.

Wathatha omnye womthwalo walotata babaleka wakhwaza lotata efuna uncedo ncedani!! Kwabe kukho umfo ongunogada wavuthela impepe ebiza abanye onogada babe abakhuthuzi bengena emotweni yabo bemka. Bafika baya emahlahleni aba bakhuthuzi bavula lemantyi kwathi gqi inyoka eyona inkulu bothuka begqa amehlo kukoyika.

Sasiyaphe ibali lam.

- Second example

English translation of first example:

The Two Robbers

One day there was an old man who was at the airport, standing in a queue, waiting for the arrival of an aeroplane.

While he was standing there two young men came and they decided to take the old man's basket. One of them went to the old man and he asked him irrelevant questions. This old man asked whether I can help you and the young man continued asking him false things. The other thief saw that he was not looking at him.

He took one of the old man's luggages, and they ran away. This old man shouted for help. Help, please!! There was a security officer who blew the whistle for the attention of other security officers while the two robbers were getting into their car and went away. They went to the forest and opened this basket. A very big snake came out and they were shocked and terrified.

There ends my story.

- Third example 
In English

Two Robbery

Once open time the was two robbery in airport. The was a man standing few line and with he's houbor.

Two robbery come behind him and saw he's barsket. One robbery go to him and ask silly things and another one take the barsket they ran away and he shout for help. The seturity blow the wesil for calling seturity's they ran away and get into they car and drive and go to the bush.

they take out the barsket and open it inside the barsket the was a big snake they fraded. that is my end of my storie.

We judge the pupils on the basis of the third example. We ignore what they can do in the mother tongue. The study showed that at Grade 4 level, the pupils performed significantly better in the Xhosa version of the narrative task. Pupil samples indicate that the Xhosa version was almost always much richer than the English version and more true to the pictures in the narrative task. In fact, at Grade 4 level, pupils expressed themselves with great difficulty in English. At Grade 7 level, although the average English performance had improved, the gap between the Xhosa and English versions remained virtually unchanged. The study also showed that pupils at this school, which is similar to many schools catering for African pupils, are not ready to switch to English as a medium at the beginning of Grade 4. One of the recommendations from this study was that Xhosa be extended as an MoI at least until the end of Grade 6.

What laypersons such as parents do not realise, is that strong proficiency in the mother tongue can assist in the acquisition of a second language such as English - a view endorsed by the Canadian scholar, Jim Cummins. He consistently argues that:

Significant positive relationships exist between the development of academic skills in first (L1) and second (L2) languages. This is true even for languages that are dissimilar (e.g. Spanish and Basque; English and Chinese; Dutch and Turkish).... The most successful bilingual programs are those that aim to develop bilingualism and biliteracy. Short-term transitional programs are less successful in developing both L2 and L1 literacy than programs such as dual language programs that continue to promote both L1 and L2 literacy throughout elementary school (2009:20, italics in the original). 
This view is borne out in many studies which focus on both L1 and L2 development (Desai 2003, 2012; Ramirez et al. 1991; Thomas and Collier 2002). Given this relationship, the L1 or mother tongue of pupils would then need to be strengthened in relation to 'standard normative varieties', so that it can enhance the acquisition of the L2. This applies particularly to written standards. The sociologist and language scholar, Kwesi Kwaa Prah, states that Africans are 'among the most multilingual people in the world'. However, he qualifies this multilingualism as follows:

This richness in command over languages is however mainly oral, with little or hardly any bases in literacy. This weakness means that the foundations of multilingualism in Africa are tenuous. It is a multilingualism which suffers from all the debilities of orality as opposed to literacy (2009:259).

Alidou (2004) also takes up this point and argues for the need to develop written materials in African languages. The concept of linguistic citizenship, discussed below, may, however, militate against developing written materials in the standard varieties of local languages.

\section{Linguistic citizenship}

A concept that has emerged recently and which is gaining ground in sociolinguistics and applied linguistics circles is 'linguistic citizenship'. It is often used as a foil for the concept of 'linguistic human rights' or 'language rights'. Stroud and Heugh (2003:18) note: 'Linguistic citizenship pertains to a view of language as a symbolic, material, intimate and global resource in the service of participatory governance.' The operative word here is 'resource'. The notion of 'linguistic citizenship' sees language as a resource that speakers can use to their advantage. Interestingly, proponents of this concept tend to imply that the benefits accruing to exercising 'multilingual repertoires' are usually realised in informal economic settings such as marketplaces. As they indicate, 'Linguistic citizenship . highlights how multilingually- constructed markets outside of the formal comprise the foremost means whereby marginalised speakers engage with a transformative politics of recognition and redistribution' (ibid:19). Language is used very broadly to refer to linguistic repertoires spanning a continuum, rather than focusing on a single language. Proponents of this concept (such as Stroud, Heugh and Blommaert) valourise 'unofficial local varieties' as opposed to what they refer to as 'essentialist identities of standard languages'. They argue that linguistic repertoires develop organically (in the marketplace and elsewhere), often across languages. According to them, an 'essentialist' focus on 
mother-tongue or standard language is not helpful, as it does not acknowledge and valourise linguistic developments 'from below' but further marginalises the marginalised.

\section{How does this relate to language and education?}

One of the purposes of education is to expose pupils to the standard variety of a language - particularly the written variety. The question that comes to mind is how this will happen (in African languages) if the focus is not on an 'essentialist' standard variety but on an unofficial local variety? Will we not be depriving pupils of epistemological access to the curriculum if we do not focus on developing competence in a standard variety? Before proceeding to discuss the second perspective I critique, namely mother tongue and essentialism, it is useful to look at definitions of 'mother tongue'.

Definitions of mother tongue

As the term 'mother tongue' is understood differently by different people, it is useful to look at how the term has been defined. Here I draw on the typology developed by Skutnabb-Kangas, which is still very much in use today.

Table 1: Skutnabb-Kangas' language typology

\begin{tabular}{|l|l|}
\hline Criterion & Definition \\
\hline 1. Origin & $\begin{array}{l}\text { the language one learned first (the } \\
\text { language one has established the } \\
\text { first long-lasting verbal contacts in) }\end{array}$ \\
\hline $\begin{array}{l}\text { 2. Identification } \\
\text { internal } \\
\text { external }\end{array}$ & $\begin{array}{l}\text { the language one identifies with/as } \\
\text { the language one is identified } \\
\text { with/as a native speaker of, by } \\
\text { others }\end{array}$ \\
\hline 3. Competence & the language one knows best \\
\hline the language one uses most
\end{tabular}

Source: Skutnabb-Kangas 2000:106.

Skutnabb-Kangas (2000:105-106) points out that 'defining "mother tongue(s)" is not only an academic exercise - it is necessary also for practical purposes ... [such as] 
(census, right to services which are given on the basis of mother tongue, assessment of linguistic qualifications for education, jobs etc.)'.

She proceeds to identify what her mother tongues are, according to the four criteria of origin, identification, competence and function. To concretise these definitions, it may be useful to apply her definitions to my own personal situation.

My mother tongue by origin is Konkani, a language spoken mainly in Goa but also in other parts of India, such as villages and towns in the state of Maharashtra. There is disagreement among linguists and educationists as to whether Konkani is a language in its own right or a variety of Marathi, the official language in Maharashtra State, but that debate is not pertinent to this description. My mother tongues by internal identification are Konkani and English, but only English by external identification. One explanation for the difference in internal and external identification is that, in South Africa, very few adults - and even fewer children - of Indian origin can speak an Indian language. Very few adults of my generation, and hardly any who are younger, actually still speak their 'languages of origin'. In South Africa, it is assumed that 'Indians' have English as their mother tongue, and in most cases such an assumption would be correct. With regard to both competence and function, my mother tongue would be English. However, if I follow Skutnabb-Kangas' approach in the description of her language biography, I could include Afrikaans under competence, even though my proficiency in Afrikaans is not as good as it is in English, when it comes to productive skills such as speaking and writing. I also have a limited competence in Xhosa (Desai 2012).

The criteria of competence and function are particularly important. There is usually a link between the two - one most frequently uses the language(s) one knows best. However, when it comes to language and education in African schools in South Africa, particularly with regard to the MoI, there is very little correlation between the two criteria. When I make a case for mother-tongue education, I am making the case with reference to the criterion of competence - the language one knows best.6 For, even though Xhosa (the specific language referred to in the Khayelitsha study) is confined to limited domains of use, it is the language the pupils know best and use most frequently at schools such as Themba Primary in Khayelitsha, where I conducted the research.

Skutnabb-Kangas (2000:111) alerts us to the fact that the definitions of mother tongue she provides may not always apply in multilingual contexts. The criterion that is most difficult to define is origin, as 'parents and children may not have the same 
mother tongue ... [in] situations where the mother tongue by origin may not be learned in infancy and may not be taught by the primary care-takers'.

I find Skutnabb-Kangas' definitions and descriptions of mother tongue helpful in discussions on language in education, since they concretely describe various applications of the use of the mother tongue in daily interaction.

\section{Mother tongue and essentialism}

In the past decade or so, a nuanced set of criticisms of mother-tongue education, drawing on critical theory and post-modernism, has emerged in recent edited collections and relevant journals (Makoni and Pennycook 2007; Pennycook 2006; Ricento 2002, 2006; Tollefson 2006). The main thrust of their criticism is directed at the ideologically-laden nature of the term 'mother tongue' and its corollary 'mother-tongue education'. Numerous arguments are raised against the use of the term 'mother tongue' (Makoni 1998, 2003; Makoni and Pennycook 2007; Pennycook 2002, 2006; Ricento 2002, 2006), some of which are listed here:

- It is difficult to determine the mother tongue in bilingual and multilingual situations (Ricento 2002);

- In some contexts children can have multiple mother tongues (Ricento 2002);

- The promotion of the mother tongue can further the status quo against the interests of marginalised groups, such as in the case of South Africa during apartheid (De Klerk 2002) or Hong Kong and Malaysia during British colonial rule (Pennycook 2002). According to De Klerk (2002:41), 'The legacy of apartheid mother-tongue promotion weighs heavily on attempts to implement multilingual policies'. She argues that the challenge for language planners is to 'reframe that legacy and harness it for democratic purposes' (ibid.);

- The use of 'vernaculars' can have negative effects on pupils, because these 'vernaculars' have 'colonised images' encoded in them (Makoni 1998);

- Promoting African languages is tantamount to a 'retrospective justification of a bygone era' (Makoni 1998);

- The essentialist status of the mother tongue as the cornerstone of language policy is questioned by Pennycook (2002) and others;

- There is a disjuncture between the 'standard' and the language used in communities with regard to African languages. According to Makoni (2003:136), 'In the case of African languages, however, the magnitude of the disjuncture is so great that there are potentially adverse effects for mother tongue education'. 
The special issue of the International Journal of the Sociology of Language Vol. 154,8 edited by Ricento and Wiley (2002), is part of this trend. Articles in this journal reinforce the view that mother-tongue education is often seen as problematic from a political, social and ideological perspective - interestingly not from a pedagogical perspective, which is the focus of this article. In the Introduction to the special issue, Ricento (2002:2) writes:

The research presented reveals, among other things, just how ideologically encumbered MT [mother tongue - ZD] is and why our understanding of contemporary language policies requires a careful analysis of the histories of all ethnolinguistic groups in contact situations, as well as an interpretive framework that resists the tendency to essentialize received categories such as language, ethnicity, identity, and most of all, mother tongue.

It is interesting to note that the first two contributors to the special issue, Pennycook and De Klerk, also suggest that proponents of mother-tongue education are essentialist in their approach. 'Essentialism' treats language, identity, ethnicity, culture and related categories as givens, rather than as negotiated. A non-essentialist approach would involve, as Pennycook (2002:25) argues:

[The need] ... to question the received categories of linguistics and applied linguistics. Such a questioning must include even those most basic concepts such as language and mother tongue. This is not to engage in questioning for its own sake but to engage with the problem that all such terms are historical constructs and carry some of the weight of that historical baggage with them.

He proceeds to qualify what he has been problematising by saying (ibid:24):

The argument that mother-tongue education may be used as part of social control does not mean we should reject the notion, but it raises concerns .. The issues I have been raising in this article do not suggest that we should abandon the notion of the mother tongue, but rather that we should understand it as a strategically essentialist (Spivak 1993) argument .... The strategic use of essentialism - whether we are claiming gendered, sexual, cultural, or linguistic identity - is useful for mobilization and legislation, but it may also reproduce those fixed categories of identity that many wish simultaneously to avoid. 
Although Pennycook sees some strategic merit in essentialist approaches to mother-tongue education, he cautions that such approaches could reproduce 'fixed categories of identity'. He provocatively questions the reification of the mother tongue:

Whether from the point of view of linguists' butterfly-collecting approach to language preservation, liberal concerns with the maintenance of diversity, or arguments in favour of individual and community rights, the mother tongue, rather like the Virgin Mary, remains something in whose direction the congregation of language educators should always genuflect (Pennycook 2002:11).

This is echoed by Makoni (1998:162-163), who is critical of African 'vernaculars' because of 'the colonised images encoded' in them:

The battle for independence is simply not won by opting for vernaculars over English as normally articulated in the decolonisation literature .... From UNESCO to the multicultural lobby the potential negative effects of learning through vernaculars is not addressed as it is assumed that it is cognitively and emotionally advantageous that a child learns through such a medium, overlooking as it does the colonized images encoded in such versions of African vernaculars.

\section{Countering the criticisms of mother-tongue education}

As Alexander propagated on numerous platforms, all languages develop dynamically through use, and African languages are no exception. During the height of the struggle against apartheid, African language speakers coined many new words and phrases to capture what was happening in the country. Granted, the difference between Xhosa and Zulu might have been accentuated by missionaries, but today these two varieties exist and are spoken by over 40 per cent of people in South Africa. What does it mean to 'disinvent' these languages, if they exist as part of the repertoires of particular speech communities? Does it mean that one ignores the existence of a particular variety? Questioning the mother-tongue argument might render one politically suspect in some circles (Pennycook 2002:12), but equally, in other circles, it has become fashionable for Africans to question mother-tongue education (Makoni 1998:162-163). The 'invention' of languages such as Xhosa or Zulu is conceded, but after a while inventions are usually accepted in societies. Is the 'invention' of Xhosa and Zulu to remain an invention and therefore to be treated with suspicion? Would the same apply to English? Makoni and Pennycook (2007:3), in their edited collection Disinventing and reconstituting languages, indicate that their 
'intention is to find ways of rethinking language in the contemporary world ... in order to provide alternative ways forward'.

It is important to note that proponents of mother-tongue education do not argue for the sole use of the mother tongue. It is not very useful polarising the role of African languages against English or another language of wider communication. Both are useful and needed.

How these languages of wider communication are learnt and taught has to be determined by the context in which they operate. For example, in Tanzania where more than 90 per cent of the population is proficient in Swahili, it makes sense to use that language as the MoI throughout school education, while acknowledging the role of English. In such a context English can be learnt as a subject. But then it needs to be taught well by people who are proficient in the language (Qorro 2009). Pupils must gain access, at the appropriate time, to reading materials in English. As Krashen (2002:148) puts it, '[f]ree reading in the second language makes a strong contribution to advanced second-language development, for the development of "academic" language. Pleasure reading appears to be the bridge leading to academic language.'

Choosing to teach English as a subject throughout the school education system, while using Swahili as the MoI, does not mean Tanzania is guilty of using a binary approach. Rather, it is choosing a language policy that will both facilitate access to knowledge and ensure that Tanzanian children gain access to a language of wider communication. In the present context, with all its resource constraints, using English as a medium simply is not working and will not work while the context remains unchanged (Qorro 2009). The data from the study done in Khayelitsha (Desai 2003, 2012) and the Language of Instruction in Tanzania and South Africa (LOITASA) project (Brock-Utne et al. 2003, 2004, 2005, 2006; Desai et al. 2010, Qorro et al. 2008) indicate that, despite the many constraints identified by Makoni and others, pupils are better able to understand what they are learning and are better able to express themselves in their mother tongue.

\section{Concluding remarks}

In a country such as South Africa, where difference has historically meant inequality, there is tremendous suspicion around mother-tongue education. It is wrongly assumed that equality equals English-medium education for all. On the contrary: equality equals mother-tongue education for all, plus effective access to English, if English is not the mother tongue of the pupils. For equal education to be realised, 
state intervention is needed. Devolving language-in-education policy decisions to often malfunctioning or poorly functioning school governing bodies constitutes an abdication of responsibility on the part of the national and provincial government. The state needs to take responsibility for language-in-education policy - certainly, at least at school level. Choices facing pupils and their parents have to be real choices, so that schools do not resort to the default positions which existed pre-1994.

Present practices still privilege English, and to a lesser extent Afrikaans-speaking pupils. For this to change, a twin-pronged thrust is needed: Expose pupils to mother-tongue education, while at the same time providing them with quality English language subject teaching. Present practices are, however, likely to continue unless speakers of African languages take up the fight for mother-tongue education - warts and all. This fight is not likely to be organised by the African elite who tend to send their children to former white, coloured or Indian schools.

The evidence points to the fact that linguistic practices from below, regardless of how creative and innovative they are, cannot change the power dynamics in unequal societies such as South Africa. Are we being entirely honest when we argue for local voice and agency, but suppress these voices in the powerful corridors of academia and in our classrooms where we valourise the standard variety of the hegemonic languages, which are usually the languages of instruction? To ensure that the multilingualism we promote is substantive, there needs to be a gradual approach of extending the nine African languages as MoI, initially until the end of Grade 6, at least. The state needs to give more direction and provide resources, particularly digital projects that will make African languages attractive to young people. As Wolff (2011:92) notes so eloquently: 'Language is not everything in education, but without language everything is nothing in education'.

\section{Notes}

1. This article draws on my doctoral dissertation (Desai 2012) and an earlier chapter on the LOITASA Project (Desai 2010).

2. One is reminded of the title of a manuscript written by Alexander (2000), 'English unassailable but unattainable'.

3. African pupils in urban areas attended schools falling under the DET during apartheid.

4. This paper was accessed via UPSpace, the Research Repository of the University of Pretoria, and was not numbered. See bibliography for actual reference details. 
5. The piece has been translated into English by a Xhosa-speaking academic who is also an educational translator.

6. I acknowledge that this may change over time for many multilingual speakers.

7. Not the real name of the school.

8. Ricento (2002:9) states in his Introduction that all the papers in the special issue were first presented at a colloquium titled 'Revisiting the mother tongue question in language policy, planning and politics' at the American Association for Applied Linguistics annual convention in March 2000 in Vancouver, B.C., Canada. The colloquium was organised and chaired by Terence Wiley. 


\section{References}

Alexander, N. 2000. English unassailable but unattainable: The dilemma of language policy in South

African education. Praesa Occasional Papers No. 3. Cape Town: Praesa.

Alexander, N. 2013. Thoughts on the new South Africa. Auckland Park: Jacana Media.

Alidou, H. 2004. Medium of instruction in post-colonial Africa. In Medium of instruction policies: Which agenda? Whose agenda?, ed. J.W. Tollefson and

A.B.M. Tsui, 195-214. Mahwah, NJ: Lawrence Erlbaum Associates.

Blommaert, J. 2001. The Asmara Declaration as a sociolinguistic problem:

Notes in scholarship and linguistic rights. Journal of Sociolinguistics 5(12):131-142.

Brock-Utne, B., Z. Desai and M. Qorro, eds. 2003. Language of instruction in Tanzania and South Africa (LOITASA). Dar es Salaam: E \& D Limited.

Brock-Utne, B., Z. Desai and M. Qorro, eds. 2004. Researching the language of instruction in Tanzania and South Africa. Cape Town: African Minds.

Brock-Utne, B., Z. Desai and M. Qorro, eds. 2005. LOITASA research in progress. Dar es Salaam: KAD Associates.

Brock-Utne, B., Z. Desai and M. Qorro, eds. 2006. Focus on fresh data on the language of instruction debate in Tanzania and South Africa. Cape Town: African Minds.

Cummins, J. 2009. Fundamental psycholinguistic and sociological principles underlying educational success for linguistic minority students. In Social justice through multilingual education, ed. T. Skutnabb-Kangas, R. Phillipson, A.K. Mohanty and M. Panda, 19-35. Bristol: Multilingual Matters.

De Klerk, G. 2002. Mother-tongue education in South Africa: The weight of history. International Journal of the Sociology of Language 154:29-46.

De Klerk, V. 2002. Language issues in our schools: Whose voice counts? Part 1: The parents speak. Perspectives in Education 20(1):1-14.

Department of Education (DoE). 1997. Language-in-education policy. Government Notice No. 383, Vol. 17997. Pretoria: Government Printers.

Desai, Z. 2003. A case for mother tongue education? In Language of instruction in Tanzania and South Africa (LOITASA), ed. B. Brock-Utne, Z. Desai and M. Qorro, 45-68. Dar es Salaam: E \& D Limited.

Desai, Z. 2010. Laissez-faire approaches to language in education policy do not work in South Africa. In Educational challenges in multilingual societies, ed. Z. Desai, M. Qorro and B. Brock-Utne, 102-112. Cape Town: African 
Minds.

Desai, Z. 2012. A case for mother tongue education? Unpublished doctoral thesis, University of the Western Cape, Bellville, South Africa

Colloquium: Multilingualism from below, University of Antwerp, Belgium, 14-16 September.

Makoni, S. and A. Pennycook, eds. 2007. Disinventing and reconstituting languages. Clevedon: Multilingual Matters.

Morrow, W. 1993. Epistemological access in the university. AD Issues 1(1):3-5. Academic Development Centre, University of the Western Cape.

Ngugi wa Thiong'o, J. 1986. Decolonising the mind. London: James Currey.

Nomlomo, V. 2007. Science teaching and learning through the medium of English and isiXhosa: A comparative study at two primary schools in the Western Cape. Unpublished doctoral thesis, University of the Western Cape, Bellville.

Pennycook, A. 2002. Mother tongues, governmentality and protectionism. International Journal of the Sociology of Language 154:11-28.

Pennycook, A. 2006. Postmodernism in language policy. In An introduction to language policy: Theory and method, ed. T. Ricento, 60-76. Oxford: Blackwell Publishing.

Prah, K. 2009. A tale of two cities: Trends in multilingualism in two African cities - the case of Nima- Accra and Katatura-Windhoek. In Multilingualism: An African advantage, ed. K. Prah and B. Brock-Utne, 250-274. Cape Town: CASAS (Book Series No. 67).

Qorro, M. 2009. Parents' and policy makers' insistence on foreign languages as media of education in Africa: Restricting access to quality education - for whose benefit? In Languages and education in Africa: A comparative and transdisciplinary analysis, ed. B. Brock-Utne and I. Skattum, 57-82. Bristol: Symposium Books.

Qorro, M., Z. Desai and B. Brock-Utne, eds. 2008. LOITASA: Reflecting on Phase 1 and entering Phase 2.

Dar es Salaam: E \& D Vision Publishing Limited.

Ramirez, D., S. Yuen and D. Ramey. 1991. Executive summary. Final report: Longitudinal study of structured English immersion strategy, early-exit and late-exit transitional bilingual education programs for language-minority children. California: Aguirre International.

Ricento, T. 2002. Introduction. International Journal of the Sociology of Language 154:1-9. 
Ricento, T. 2006. Language policy: Theory and practice - an introduction. In $A n$ introduction to language policy: Theory and method, ed. T. Ricento, 10-23. Oxford: Blackwell Publishing.

Skutnabb-Kangas, T. 2000. Linguistic genocide in education - or worldwide diversity and human rights? Mahwah, NJ: Lawrence Erlbaum.

Stroud, C. and K. Heugh. 2003. Language rights and linguistic citizenship. In Language policy and democracy in South Africa: The prospects of equality within rights-based policy and planning, ed.

K. Heugh, Study 7, 1-27. Stockholm: Centre for Research on Bilingualism, Stockholm University.

Thomas, W.P. and V.P. Collier. 2002. A national study of school effectiveness for language minority students' long-term academic achievement. George Mason University, CREDE (Center for Research on Education, Excellence).http://www.crede.ucsc.edu/research/llaa/1.1_final.html (accessed 6 January 2012).

Tollefson, J.W. 2006. Critical theory in language policy. In An introduction to language policy: Theory and method, ed. T. Ricento, 42-59. Oxford: Blackwell Publishing.

Tsui, A.B.M. and J.W. Tollefson, eds. 2004. The centrality of medium-of-instruction policy in sociopolitical processes. In Medium of instruction policies: Which agenda? Whose agenda?, ed. J.W. Tollefson and A.B.M. Tsui, 1-18. Mahwah, NJ: Lawrence Erlbaum.

Wolff, H.E. 2006. Background and history: Language politics and planning in Africa. In Optimising learning, education and publishing in Africa: The language factor. A review and analysis of theory and practice in mother-tongue and bilingual education in sub-Saharan Africa, ed. A. Ouane and C. Glanz, 49-102. Hamburg, Germany and Tunis Belvedere, Tunisia: UNESCO Institute for

Lifelong Learning (UIL) and the Association for the Development of Education in Africa (ADEA). 